\title{
Mobility of lithium ions in anodic alumina formed on an $\mathrm{Al}-\mathrm{Li}$ alloy
}

\author{
K. Tzoganakou ${ }^{\mathrm{a}}$, P. Skeldon ${ }^{\mathrm{a}, *}$, G.E. Thompson ${ }^{\mathrm{a}}, \mathrm{X}$. Zhou ${ }^{\mathrm{a}}$,

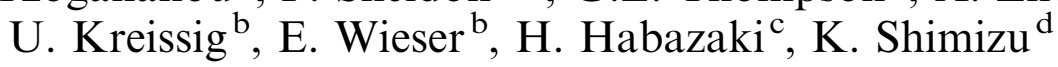 \\ ${ }^{\mathrm{a}}$ Corrosion and Protection Centre, University of Manchester Institute of Science and Technology, P.O. \\ Box 88, Manchester M60 1QD, UK \\ ${ }^{\mathrm{b}}$ Forschungszentrum Rossendorf e.V., Institute of Ion Beam Physics and Materials Research, P.F. 510119 , \\ D-01314 Dresden, Germany \\ ${ }^{\mathrm{c}}$ Institute for Materials Research, Tohoku University, 2-1-1 Katahira, Aoba-Ku, Sendai 980-77, Japan \\ ${ }^{\mathrm{d}}$ University Chemical Laboratory, Keio University, 4-1-1 Hiyoshi, Yokohama 223, Japan
}

Received 3 September 1999; accepted 15 October 1999

\begin{abstract}
The mobility of lithium species in the barrier anodic film formed on an Al-3 at\% Li alloy in ammonium pentaborate electrolyte has been determined from measurements of film composition by glow discharge optical emission spectroscopy and elastic recoil detection analysis. The results reveal the presence of lithium species throughout the thickness of the anodic film, with a reduced amount of lithium in the film compared with that in the alloy. The level of reduction in lithium content indicates that lithium species migrate outward about eight times faster than $\mathrm{Al}^{3+}$ ions. The lithium species are lost to the electrolyte on reaching the film/electrolyte interface, leading to a slight loss in the efficiency of film growth. In contrast, aluminium species are retained within the film, as revealed by the distribution of boron in the outer $\sim 40 \%$ of the film thickness. Determination of hydrogen profiles indicates insignificant amounts of hydrogen in the film. (C) 2000 Elsevier Science Ltd. All rights reserved.
\end{abstract}

\footnotetext{
* Corresponding author. Tel.: +44-0161-200-4872; fax: +44-0161-200-4865.

E-mail address: p.skeldon@umist.ac.uk (P. Skeldon).
} 


\section{Introduction}

Lithium is one of the important strengthening elements of commercial, precipitation-hardened, 8000 series aluminium alloys [1], which are normally subjected to surface treatment prior to service [2]. The pre-treatments commonly develop amorphous alumina films, sometimes hydrated, on the alloy surface; examples are acid pickling, alkaline etching, conversion coating and anodizing. From findings of previous work on aluminium alloys, it is anticipated that lithium atoms in solid solution in matrix regions of the alloy are incorporated immediately into the growing amorphous alumina films, presumably as $\mathrm{Li}^{+}$ions, which migrate outward faster than $\mathrm{Al}^{3+}$ ions [3]. The immediate incorporation of lithium species is associated with the lower Gibbs free energy per equivalent for formation of $\mathrm{Li}_{2} \mathrm{O}$ compared with that for formation of $\mathrm{Al}_{2} \mathrm{O}_{3}$, while the faster migration of $\mathrm{Li}^{+}$ions relates to the lower energy of the $\mathrm{Li}^{+}-\mathrm{O}$ bond compared with that of the $\mathrm{Al}^{3+}-\mathrm{O}$ bond [4]. Thus, lithium is not expected to enrich in the alloy as a consequence of film growth. Further, the $\mathrm{Li} / \mathrm{Al}$ atomic ratio in the alumina film material should be less than that in the alloy by a factor dependent on the relative mobilities of $\mathrm{Li}^{+}$and $\mathrm{Al}^{3+}$ ions. Due to the faster migration of $\mathrm{Li}^{+}$ions, there is a possibility of formation of an outer film layer composed initially of $\mathrm{Li}_{2} \mathrm{O}$ or $\mathrm{LiOH}$, depending upon the composition and $\mathrm{pH}$ of the environment [3]. If the efficiency of film growth is reduced, with lithium and possibly also aluminium species entering the solution, precipitated material may deposit at the film surface.

In the present work, the formation of a barrier anodic film, which is a model system for amorphous oxide films generally, is examined for a solid solution Al-3 at $\% \mathrm{Li}$ alloy. The complementary techniques of elastic recoil detection analysis (ERDA), providing quantification of composition [5], and glow discharge optical emission spectroscopy (GDOES), providing enhanced depth resolution and sensitivity to lithium [6], are employed to determine the amount and distribution of lithium species in the film.

\section{Experimental}

\subsection{Specimen preparation}

Specimens of Al-3 at\% Li alloy, of approximately $6 \mathrm{~cm}^{2}$ working area, in the solution-treated condition ( $853 \mathrm{~K}$ for $60 \mathrm{~min}$, followed by quenching to $273 \mathrm{~K}$ ) were electropolished at $20 \mathrm{~V}$ for $300 \mathrm{~s}$ in perchloric acid/ethanol $(20 / 80$ by volume) electrolyte at $278 \mathrm{~K}$. The specimens were then anodized at $5 \mathrm{~mA} \mathrm{~cm}{ }^{-2}$ to $150 \mathrm{~V}$ in $0.1 \mathrm{M}$ aqueous ammonium pentaborate electrolyte $(\mathrm{pH} \mathrm{8.2)}$ at $292 \mathrm{~K}$. The voltage-time responses were recorded during anodizing. After both electropolishing and anodizing treatments, the specimens were rinsed in deionized water and dried in a cool air stream. For comparison purposes, electropolished 
99.99\% aluminium was anodized under the same conditions, which result in film growth at almost $100 \%$ efficiency with a $\mathrm{nm} \mathrm{V}^{-1}$ ratio of 1.2 [7].

\subsection{Specimen examination}

GDOES analysis was carried out using a Jobin-Yvon 5000 RF spectrometer, with film sputtering in 3-5 torr argon at $13.56 \mathrm{MHz}$ and $40 \mathrm{~W}$. Composition profiles were obtained at a sampling rate interval of $0.01 \mathrm{~s}$, with monitoring of the 396, 671, 250 and $122 \mathrm{~nm}$ wavelengths for emissions from aluminium, lithium, boron and hydrogen, respectively.

The ERDA analysis employed a $35 \mathrm{MeV} \mathrm{Cl}^{7+}$ ion beam, of area $1 \times 0.5 \mathrm{~mm}$ and with a current of $6 \mathrm{nA}$, supplied by the Rossendorf $5 \mathrm{MV}$ tandem accelerator. The elastically scattered chlorine ions and the recoiled atoms were detected using a time-of-flight energy (ToF-E) telescope at a scattering angle of $45^{\circ}$ to the incident beam. The telescope consisted of a thin carbon foil, positioned near to the specimen, combined with an MCP detector to generate the start signal and a $450 \mathrm{~mm}^{2} \mathrm{Si}$ detector at the end of a $1050 \mathrm{~mm}$ flight path to provide both a time stop and an energy signal for each detected particle. Hydrogen recoils were measured by means of a Si- $\Delta \mathrm{E}-\mathrm{E}$ telescope with an aluminium range foil. The data were stored event-by-event in a two-dimensional spectrum, namely yield as a function of time-of-flight and energy, and converted to concentration-depth profiles using a computer code [8]. The depth resolution, determined by the energy resolution of the ToF-E telescope, was $\sim 70 \mathrm{~nm}$. The detection limit, determined by the acceptance angle of the telescope, was $\sim 0.1 \mathrm{at} \%$.

The surfaces of anodized specimens were examined in an Amray 1810 scanning electron microscope.

\section{Results}

\subsection{Anodizing behaviour}

The voltage-time response during anodizing of the alloy was linear, with slope $2.1 \pm 0.1 \mathrm{~V} \mathrm{~s}^{-1}$ compared with $2.3 \pm 0.1$ for anodizing high purity aluminium, indicating film growth on the alloy at relatively high efficiency.

\subsection{GDOES analysis}

The GDOES composition profile for a specimen of the anodized Al-3 at $\% \mathrm{Li}$ specimen reveals the typical, slowly rising signal from aluminium in the anodic film [6], prior to a rapid increase for the alloy substrate (see Fig. 1). Lithium species are present throughout the anodic film, with their profile, following closely that for aluminium, indicating a relatively uniform distribution. There is no evidence of an outer, lithium-rich layer above the main, alumina-rich film material. Significantly, the film contains boron species, derived from the 
electrolyte, in the outer part of the film thickness. The ratio of the thickness of film material containing boron species to the total thickness of the film is about 0.44 , assuming as usual that the boundary between the boron-containing and boron-free regions is located at one-half the maximum of the boron signal [6]. A very low signal is disclosed for hydrogen in the film, which is consistent with the quantitative analysis by later ERDA.

\subsection{ERDA analysis}

The two-dimensional ERDA spectra for a specimen anodized in the same manner as that analysed by GDOES discloses stripes for aluminium, lithium, oxygen and boron species in the anodic film and chlorine from the ion beam (see Fig. 2). Interpretation of the data [8] reveals the distributions of the species through the film thickness (see Fig. 3). Aluminium and oxygen are present throughout the film with an average $\mathrm{O} / \mathrm{Al}$ atomic ratio of $1.6 \pm 0.1$, consistent with a film composed mainly of anodic alumina. Lithium species are distributed throughout the film, while boron species are present in the outer one-half of the film. The $\mathrm{Li} / \mathrm{Al}$ atomic ratios for the film and alloy are $8.6 \pm 1.4 \times 10^{-3}$ and $3.4 \pm 0.3 \times 10^{-2}$, the reduced ratio for the film compared with the alloy indicating that the mobility of lithium species is greater than that of $\mathrm{Al}^{3+}$ ions. The amount

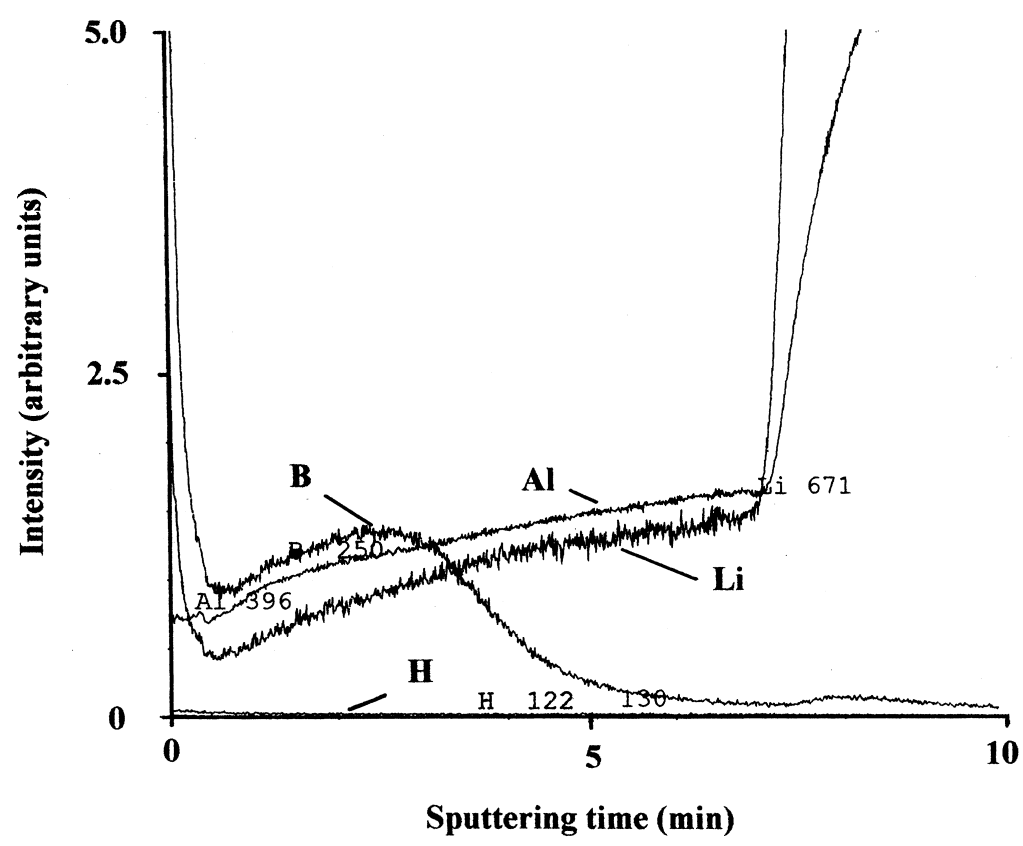

Fig. 1. GDOES composition profiles for the $\mathrm{Al}-3$ at $\% \mathrm{Li}$ alloy anodized at $5 \mathrm{~mA} \mathrm{~cm}{ }^{-2}$ to $150 \mathrm{~V}$ in 0.1 M ammonium pentaborate electrolyte at $292 \mathrm{~K}$. 


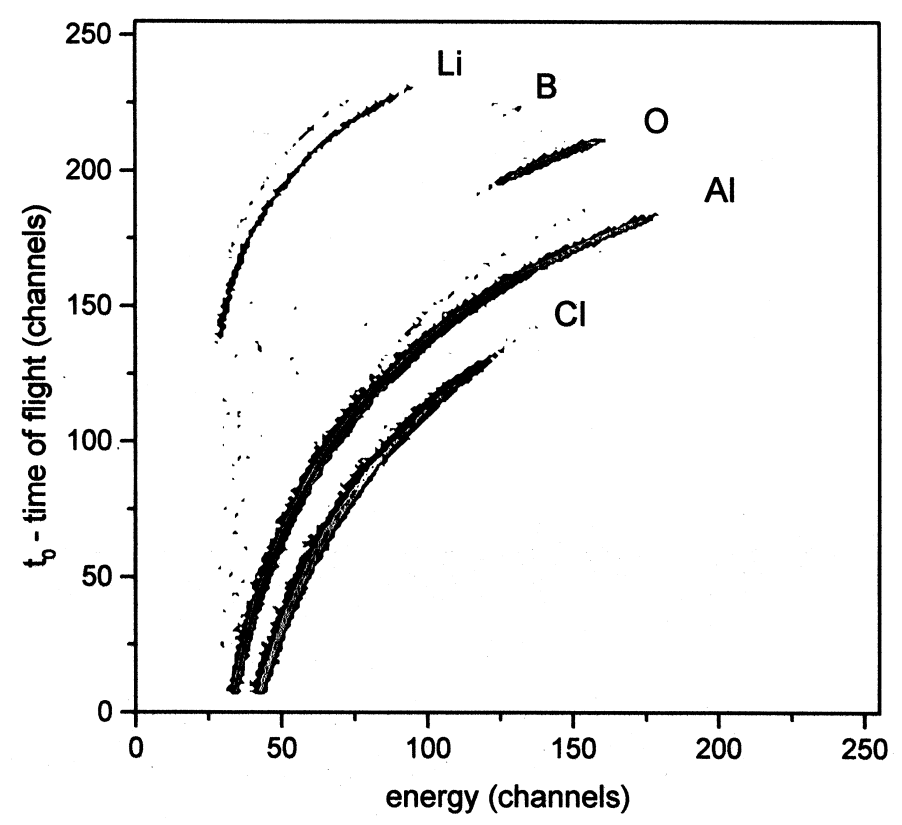

Fig. 2. Two-dimensional time-of-flight versus energy ERDA spectra for the Al-3 at $\%$ Li alloy anodized at $5 \mathrm{~mA} \mathrm{~cm} \mathrm{c}^{-2}$ to $150 \mathrm{~V}$ in $0.1 \mathrm{M}$ ammonium pentaborate electrolyte at $292 \mathrm{~K}$.

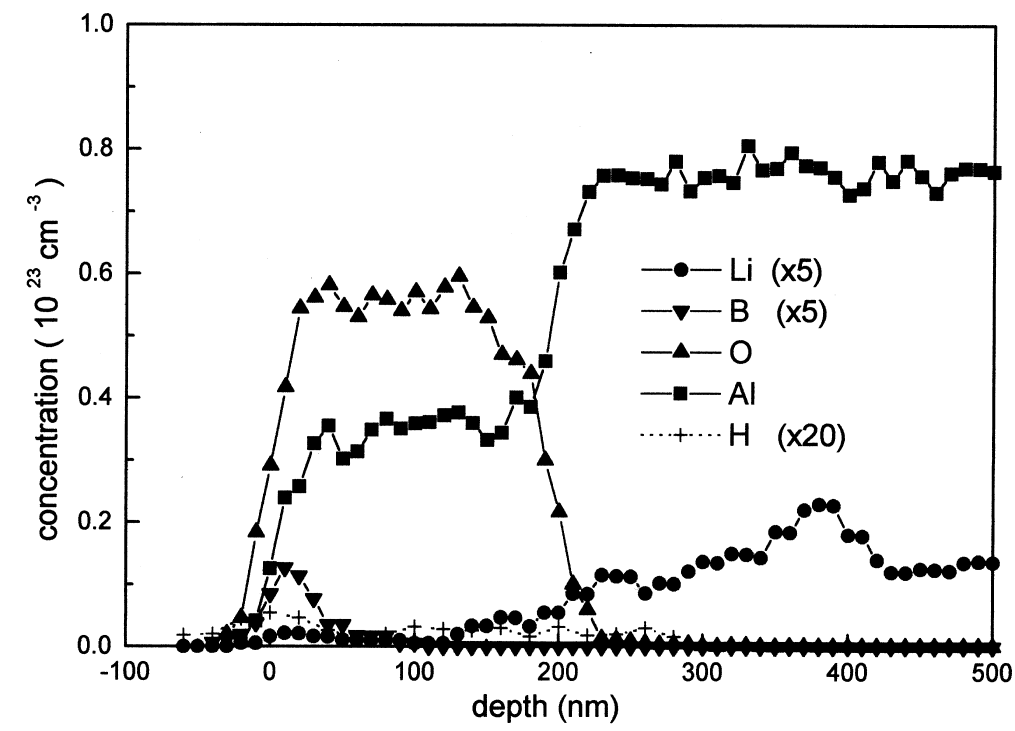

Fig. 3. Composition profiles, derived from the ERDA data of Fig. 2, for the Al-3 at $\%$ Li alloy anodized at $5 \mathrm{~mA} \mathrm{~cm}^{-2}$ to $150 \mathrm{~V}$ in $0.1 \mathrm{M}$ ammonium pentaborate electrolyte at $292 \mathrm{~K}$. 
of boron in the film is $1.5 \pm 0.3 \times 10^{16}$ boron atoms $\mathrm{cm}^{-2}$; the boron species are contained mainly within a layer of film material adjacent to the film/electrolyte interface of thickness within the depth resolution of about $40 \mathrm{~nm}$. The measurement of hydrogen content revealed that the film contains a uniformly low amount of hydrogen, corresponding to a $\mathrm{H} / \mathrm{Al}$ atomic ratio of $4.3 \pm 0.3 \times 10^{-3}$.

\subsection{Scanning electron microscopy}

In order to determine the effect of lithium oxidation and incorporation into the anodic alumina on the adhesion of the anodic film to the alloy, adhesive tape was attached to the filmed alloy and then removed immediately from the surface. Examination of the specimen revealed partial removal of the film from the alloy substrate (see Fig. 4). In contrast, no film material was removed when the same procedure was applied to anodized aluminium.

\section{Discussion}

Anodizing of aluminium under the present conditions is known to occur at an efficiency approaching $100 \%$, with film growth proceeding at both the film/ electrolyte and metal/film interfaces due to co-operative transport of $\mathrm{Al}^{3+}$ and $\mathrm{O}^{2-}$ ions, respectively [9]. Boron species, which are immobile in the film, are found throughout the thickness of material formed at the film/electrolyte interface; this outer layer constitutes about $40 \%$ of the film thickness [10]. The small amount of lithium species in the film formed on the $\mathrm{Al}-3$ at $\% \mathrm{Li}$ alloy, corresponding to a $\mathrm{Li} / \mathrm{Al}$ atomic ratio of about 0.01 , is unlikely to affect significantly the mechanism of formation of anodic alumina. Thus, the distribution of boron, determined by GDOES, in the anodic film formed on the

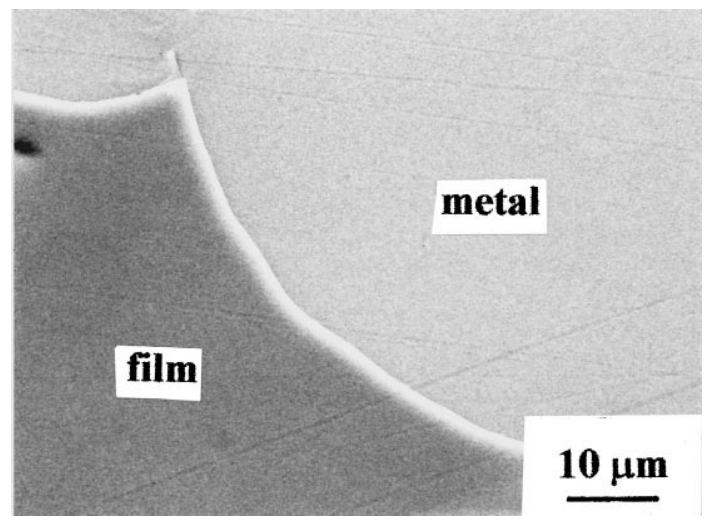

Fig. 4. Scanning electron micrograph of the anodic film formed on the 3 at $\%$ Li alloy anodized at 5 $\mathrm{mA} \mathrm{cm}{ }^{-2}$ to $150 \mathrm{~V}$ in $0.1 \mathrm{M}$ ammonium pentaborate electrolyte at $292 \mathrm{~K}$. Partial detachment of the film, due to stripping with adhesive tape, is disclosed. 
alloy indicates that the film is formed at high efficiency, with negligible loss of aluminium species to the solution. The amount of boron in the film, determined by ERDA, about $1.5 \times 10^{16}$ boron atoms $\mathrm{cm}^{-2}$, is similar in magnitude to that determined in a previous study of films formed under the present conditions on aluminium, $\sim 1.8 \times 10^{16}$ boron atoms $\mathrm{cm}^{-2}[10]$. The difference in the distribution of boron in the film as determined by GDOES and ERDA, which is not important to the main interest of the study, may be due to the lower sensitivity of ERDA for detection of boron compared with that of GDOES, or a slightly reduced efficiency of anodizing for the ERDA specimen.

The relatively uniform distribution of lithium species throughout the thickness of the film and the reduced amount of lithium in the film compared with that in the alloy reveal a faster migration rate of lithium species compared with that of $\mathrm{Al}^{3+}$ ions by a factor of $8 \pm 2$. The relative migration rate is obtained from the expression

$$
r=\left(0.6+0.4 u_{0}\right)^{-1}
$$

in which $r$ is the $\mathrm{Li} / \mathrm{Al}$ atomic ratio for the anodic film divided by that for the alloy and $u_{0}$ is the migration rate of lithium species divided by that for $\mathrm{Al}^{3+}$ ions [11]. The faster migration rate of lithium species can be correlated with the lower $\mathrm{Li}^{+}-\mathrm{O}$ bond energy compared with that for $\mathrm{Al}^{3+}-\mathrm{O}$, namely 146 and $281 \mathrm{~kJ}$ $\mathrm{mol}^{-1}$, respectively [4]. Further, the migration of lithium species does not correlate with ionic radii, which are 0.59 or 0.76 for $\mathrm{Li}^{+}$ions with respective co-ordination numbers of 4 and 6 and $0.39,0.48$ or 0.54 for $\mathrm{Al}^{3+}$ ions with respective coordination numbers of 4,5 and 6 [12]. It is probable that lithium species participate in the co-operative ionic transport process associated with film growth, such that the relative migration rate of lithium species is approximately independent of the rate of film growth.

The lithium species which reach the film/electrolyte interface are lost to the electrolyte, rather than forming an outer, lithium-rich layer, since lithium oxide dissolves at the $\mathrm{pH}$ of the ammonium pentaborate electrolyte [13]. However, the influence of this loss of lithium species on the efficiency of film growth is minor, due to relatively low concentration of lithium in the alloy.

The anodic film contains very low concentrations of hydrogen, with a $\mathrm{H} / \mathrm{Al}$ atomic ratio of about $4.3 \times 10^{-3}$. Similarly low levels were detected in the aluminium substrate. Thus, the presence of $\mathrm{OH}^{-}$ions in the film is negligible, which is consistent with previous studies of amorphous barrier films grown on high purity aluminium [14]; however, increased amounts of hydrogen are reported for films grown under condition in which surface hydration may occur [14, 15]. It is possible that the small amounts of hydrogen detected in the present films are associated with modified film material formed at flaw sites in the films.

The present analyses were not sufficiently sensitive to investigate whether or not lithium is enriched in the alloy immediately adjacent to the alloy/film interface. However, the general anodic oxidation behaviour of aluminium alloys indicates that enrichment does not occur [3]. Thus, lithium and aluminium atoms are 
oxidized from the commencement of anodizing and are incorporated into the anodic film in their alloy proportions. The oxidation of lithium is presumed to form units of $\mathrm{Li}_{2} \mathrm{O}$, which are incorporated into the amorphous anodic alumina. However, the volume of oxide formed by oxidation of lithium is significantly less than that formed by oxidation of aluminium, with Pilling-Bedworth ratios (volume per metal ion in the oxide: volume per metal atom in the metal) for $\mathrm{Al}_{2} \mathrm{O}_{3} / \mathrm{Al}$ and $\mathrm{Li}_{2} \mathrm{O} / \mathrm{Li}$ of about 1.65 and 0.57 , respectively. Thus, as discussed in detail elsewhere [16], voids develop at the alloy film interface, ultimately resulting in ready detachment of the film from the alloy substrate with sufficient progress of anodizing and hence, extension of voids [17]. For the present example, the anodizing time was insufficient for spontaneous detachment of the film, but the film, with the adhesion weakened by still growing voids, was removed easily by tape.

\section{Conclusions}

1. Anodizing of Al-3 at \% Li alloy, in the solution-treated condition, at $5 \mathrm{~mA}$ $\mathrm{cm}^{-2}$ in ammonium pentaborate electrolyte at $292 \mathrm{~K}$ results in formation of an anodic alumina film contaminated uniformly by lithium species.

2. The lithium species incorporated into the anodic film migrate outward about eight times faster than $\mathrm{Al}^{3+}$ ions, which is associated with a reduced energy of the $\mathrm{Li}^{+}-\mathrm{O}$ bond compared with that of the $\mathrm{Al}^{3+}-\mathrm{O}$ bond.

3. The film forms at relatively high efficiency, with incorporation of immobile boron species into the outer $\sim 40 \%$ of the film thickness, but with loss of lithium species to solution on reaching the film/electrolyte interface.

4. The adhesion of the film formed on the Al-Li alloy is weak compared with that on aluminium, which is due to the development of voids at the metal/film interface associated with the reduced Pilling-Bedworth ratio for $\mathrm{Li} / \mathrm{Li}_{2} \mathrm{O}$ relative to that for $\mathrm{Al} / \mathrm{Al}_{2} \mathrm{O}_{3}$.

\section{References}

[1] A. Lou, D.J. Lloyd, A. Gupta, W.V. Youdelis, Acta Met. Mater. 41 (1993) 769.

[2] S. Wernick, R. Pinner, The Surface Treatment and Finishing of Aluminium and its Alloys, Robert Draper, Teddington UK, 1972.

[3] H. Habazaki, K. Shimizu, P. Skeldon, G.E. Thompson, G.C. Wood, X. Zhou, Trans. Inst. Met. Finish. 75 (1997) 18.

[4] K. Shimizu, K. Kobayashi, J. Surf. Finish. Soc. Jpn 46 (1995) 402.

[5] W.M. Arnold Bik, F.H.P.M. Habraken, Rep. Prog. Phys. 56 (1993) 859.

[6] K. Shimizu, G.M. Brown, H. Habazaki, K. Kobayashi, P. Skeldon, G.E. Thompson, G.C. Wood, Surf. Interface Anal. 27 (1999) 24.

[7] A.C. Harkness, L. Young, Can. J. Chem. 44 (1966) 2409. 
[8] C. Spaeth, F. Richter, S. Grigull, U. Kreissig, Nucl. Instrum. Meth. in Phys. Res. B140 (1998) 243.

[9] F. Brown, W.D. Mackintosh, J. Electrochem. Soc. 120 (1973) 1096.

[10] P. Skeldon, K. Shimizu, G.E. Thompson, G.C. Wood, Surf. Interface Anal. 5 (1983) 252.

[11] H. Habazaki, K. Shimizu, P. Skeldon, G.E. Thompson, G.C. Wood, Phil. Mag. B73 (1996) 445.

[12] D.R. Lide (Ed.), Handbook of Physics and Chemistry, CRC Press, NY, 1978.

[13] M. Pourbaix, Atlas of Electrochemical Equilibria of Metals in Aqueous Solutions, National Association of Corrosion Engineers, Houston, TX, 1974.

[14] W.A. Lanford, R.S. Alwitt, C.K. Dyer, J. Electrochem. Soc. 127 (1980) 405.

[15] M.F. Abd Rabbo, J.A. Richardson, G.C. Wood, Electrochim. Acta 22 (1977) 1375.

[16] I. Felhosi, H. Habazaki, K. Shimizu, P. Skeldon, G.E. Thompson, G.C. Wood, X. Zhou, Corros. Sci. 40 (1998) 2125.

[17] X. Zhou, G.E. Thompson, P. Skeldon, G.C. Wood, H. Habazaki, K. Shimizu, Corrosion 55 (1999) 561. 